International Journal of Engineering \& Technology, $7(4.7)(2018) 61-66$
International Journal of Engineering \& Technology
SPC
Website: www.sciencepubco.com/index.php/IJET
Research paper

\title{
Mediating role of Innovation and Moderating Role of Size of Enterprise over the Relationship between Entrepreneurial Orientation and Performance of Micro and Small Enterprises
}

\author{
1Yousif Riyadh Mahmood, 2Khitam Dekhn Hamzah \\ 1College of Administration and Economics, University of Al-Qadisiyah \\ 2Department of Physical Education and Sports Sciences, College of Education for Girls \\ 1yousifriyadh83@gmail.com,2khetamhamza184@gmail.com, \\ Corresponding Author:*muzaffar.asad@ucp.edu.pk
}

\begin{abstract}
In this study the authors tried to identify mediating role of innovation and moderating role of size of enterprise in the relationship between entrepreneurial orientation and performance of Micro and Small Enterprises (MSEs). The researchers also investigated the effect that vary from enterprise size that basically means micro and small enterprises. For the purpose of this study data was collected from 384 MSE's operating in Punjab province. Initially the data was analyzed using SPSS 22 and later on for the development of structure equation modeling Smart PLS-3 was used. Only two aspects of entrepreneurial orientation have been analyzed; first one is risk taking and second one is pro-activeness, third most common aspect innovation has been taken as mediating variable as an enterprise cannot be innovative if it has not the capacity of risk taking and pro-activeness. These both aspects are attached to performance and also deals with innovation. The major contribution of the study is to identify any moderating effect of size of the enterprise over the relationship between entrepreneurial orientation, innovation and performance of MSEs. These elements basically show the contribution that is made by the innovation and performance of the MSE's. The objectives of the study were achieved, and it was found that there is no difference between performance of MSEs on the basis of entrepreneurial orientation and innovation. It is proved that the size of the enterprise is not the factor. The linkages found are affected by size of the enterprises.
\end{abstract}

Keywords Entrepreneurship, Innovation, Micro and small enterprises, Performance, Risk taking.

\section{Introduction}

In the past few years business activities have increased, and dynamics of businesses have caused complexities in the business environment leading to need for innovation (Ahlin, Drnovšek, \& Hisrich, 2013). Due to great competition in the global market enterprises are in competition according to their capabilities which differentiate them from their competitors (Aloulou \& Fayolle, 2005). Many enterprises have made competitive advantage by brining innovation in their products and services (Ashourizadeh, Chavoushi, \& Schøtt, 2014). Majority of the studies conducted in the past, have focused on large enterprises only. Despite the importance of MSEs in economic development, and employment generation (Ali, 2013), MSE's are still ignored and there is little understanding that how MSEs can utilize their capabilities like entrepreneurial orientation and innovation, both these capabilities bring change towards better performance.

The MSEs contribute a lot in the economy of any developing country and Pakistan has no exception to it (Aftab \& Naveed, 2013). Pakistan is becoming the most important place for research in Asia due to declining position of small sector due to which the country has gained importance in the eyes of practitioners, researchers, and policy makers (Abe, Troilo, Juneja, \& Narain, 2012). The growth rate of small sector is declining and has remained below the acceptable average level in the last six years. The growth rate of small scale has remained below 10 percent which is an alarming situation for Pakistan (Aslam, 2013), as this sector provide maximum employment to the industrial labor force. Considering the declining position of MSEs in the country the current study tries to focus on identifying any moderating effect of size and mediating effect of innovation between the relationship among risk taking, pro-activeness, and performance of MSEs (Brettel, Chomik, \& Flatten, 2015). The research argues on facilitating entrepreneurial orientation and innovative capabilities to MSEs for gaining high performance of MSEs.

The studies have shown that Small and Medium Enterprises (SMEs) are more into new and emerging technologies and they are more into innovation but the situation for MSEs is not clear, that how to use these capabilities. MSEs are ambiguous in understanding that how can they help themselves in the process of differentiation and how this differentiation will affect their performance. Risk taking is considered as vital for SMEs and large enterprises only (Simon, Stachel, \& Covin, 2011). Similarly, pro-activeness is also considered as vital for the growth and performance of large enterprises (Runyan, Droge, \& Swinney, 2008), whereas, this study argues that MSEs operate in the same environment, so they also have the same issue and need the same to perform well. Innovation is necessary for MSEs as well (Julia, Daniel, \& Raquel, 2011). Similarly, size of the enterprise not only influence the performance of large enterprises but also the performance of MSEs (Inmyxai \& Takahashi, 2010). Usually entrepreneurial orientation is considered as the combination of innovation, risk taking, and pro-activeness (Aloulou \& Fayolle, 2005). However, the argument 
that is raised in the study is that innovation is the consequence of risk taking and pro-activeness (Hafeez, Shariff, \& Lazim, 2012). If any enterprise does not possess risk taking and is not pro-active, it can never be innovative. Therefore, the objective of current study is to focus on mediating role of innovation between risk taking, pro-activeness, and performance of MSEs, and to analyze if size of the enterprise moderates the relationship between risk taking, pro-activeness, innovation, and performance of MSEs.

\section{Literature Review}

In order to understand the phenomenon, abridged literature has been reviewed regarding performance of MSEs, entrepreneurial orientation, innovation, and size of enterprises. The enterprises must use higher skills and expertise to achieve competitive advantages. Entrepreneurial and innovative skills are the most important skills that can create a positive effect on the performance of MSEs. Most of the MSEs face constrain regarding resources and they because of that they fail to become a successful innovator. Entrepreneurial activities are said to be the nimbler activities and they are more than the counterparts. The advantage for the entrepreneurial enterprises is that they serve the attractive niches with innovation and that can simply be done through the new products in the market. Entrepreneurship qualities are attached with the learning, integrated market and lead to innovation.

Performance of MSEs in developing countries is mainly dependent on the financial resources. Majority of the researchers argued that financial access is the most common problem behind poor performance and deteriorating rate of MSEs in developing countries (Asad, Sharif, \& Alekam, 2016). The focus of the current study is that beside financial access entrepreneurial orientation is among the top most requirements for getting high performance of MSEs.

Several studies have identified the importance of entrepreneurial orientation for gaining high performance of MSEs. According to Aloulo and Fayolle (2005) risk taking is among the top most characteristic of an enterprise that may lead to high performance. Proactiveness is also given top priority (Andersona \& Eshima, 2013). Risk taking and pro-activeness both are considered important for the performance of enterprises along with innovation. The fact is that tendency to take risk and being pro-active leads to innovativeness, which causes high performance.

Several studies have identified the role of size of the enterprise as a vital element of performance (Greene, Brush, \& Brown, 2015). The size of enterprise does not directly affect performance but influences the relationship of risk taking, pro-activeness, innovation, and performance. If an enterprise has relatively bigger size its risk taking, and pro-activeness would more significantly affect performance likewise, if the size of enterprise is large it would be more prone to innovativeness as it has the capacity to face any failure (O'Regan \& Ghobadian, 2004). Therefore, in this study innovation has been taken as a mediator, whereas size of the enterprise has been taken as moderator.

Considering the importance of entrepreneurial orientation for getting high performance of MSEs, it is important to understand the concept of entrepreneurial orientation (Covin \& Lumpkin, 2011). The term entrepreneurial orientation shows that entrepreneurial orientation is basically innovativeness, pro-activeness, and risk taking behavior (Shabbir, Shariff, \& Shahzad, 2016b, 2016c, 2016a; Shabbir, Shariff, Yusof, Salman, \& Hafeez, 2018). These three behaviors create value in the culture of the enterprises (Rauch, Wiklund, Lumpkin, \& Frese, 2009). The study explains that entrepreneurial orientation is said to be the organizational culture that is used to enhance the wealth and that can be done through innovation, while looking at the opportunities. These things may bring the risk-taking prosperity for them (McMullen \& Shepherd, 2006). In entrepreneurial orientation the pro activeness is said to be the dimension and entrepreneurial chart include this orientation and shows the behavior that how much enterprises are into risk taking and they actually want to innovate by the use of available resources (Madsen, 2007). The enterprises that are in the entrepreneurial activities have intelligence, that how they will innovate and how they will bring improvement in results for the enhancement of consumers' satisfaction which will lead these enterprises among high performers (Lechner \& Gudmundsson, 2012).

Risk taking basically means taking bold decisions and the owners of MSEs have to take bold decisions when they are unknown to market situations and have to allocate resources for the success of venture (McMullen \& Shepherd, 2006). Thus, new and some of the old entrepreneurs, reported risk as the main characteristic of entrepreneurial orientation (Aloulou \& Fayolle, 2005; Asad, Sharif, \& ALekam, 2016). The basis reason innovation is linked with risk and entrepreneurial orientation is that these entrepreneurs have more impact on innovation (Brettel, Chomik, \& Flatten, 2015). They are more into capabilities to show maximum amount of performance of the entrepreneurial ventures. Entrepreneurs calculate risk and then they take the decisions (McMullen \& Shepherd, 2006). The entrepreneurial ventures are mostly linked with risk taking behavior (Rosenbusch, Brinckmann, \& Bausch, 2011). This behavior can be observed as entrepreneurs enter in to unknown markets, or enter into untested markets and adopt unproven technologies, all this required investment which is in actual financial risks. Enterprises at times just to extend the resources have to take the large amount of loans which makes the venture riskier (Ashourizadeh, Chavoushi, \& Schøtt, 2014).

Being initiative is also one of the main factors of entrepreneurial orientation (Lee, Florida, \& Acs, 2004). Taking initiative is the result of pro activeness which is among the most common characteristic of entrepreneurship. Pro activeness include catering the opportunity (Kreiser, Marino, Kuratko, \& Weaver, 2013). Basically, it means looking forward or spending time for the development of something new (Lee, Florida, \& Acs, 2004). The innovation may be in services or in products (Julia, Daniel, \& Raquel, 2011). Proactive entrepreneurs want to bring something new to the market and want to meet the demands of consumers. Entrepreneurs basically identify new opportunities by looking at the environmental situations (Shabbir, Mohd Shariff, Kiran, Faisal, \& Shahzad, 2016; Shabbir, Shariff, Salman, \& Shabbir, 2017).

Micro and small enterprise have the ability to move fast and are more flexible in the work, proactive and risk takers. The tailored niches are the most attractive niches that include introduction of innovation in products and services, including business models. It provide opportunity to the MSE's and they can provide higher value to customers and can bring uniqueness because of innovation, which ultimately leads to better performance of MSEs (Sahut \& Peris-Ortiz, 2013).

At the same time innovation is the element which now a day's decide and determine that what the organization will achieve and how it affects performance (Andersson \& Lööf, 2012). The enterprises have greater capacity to innovate and to implement innovations that are made in accordance with the market needs (Kovaleva \& Vries, 2016). Through innovation most of the organizations achieve competitive advantage and are more responsible in dealing with the environment and developing new capabilities (Aribaba, Asaolu, \& Olaopa, 2011). This act helps MSEs in enhancing performance. Innovation of the products may increase demand of the products which consequently enhances the performance (Rubera \& Kirca, 2012).

After determining the most influential factors affecting performance the important is to identify how to measure performance. The performance of any enterprise can be measured by measuring Return on Asset (ROA) and Return on Investment (ROI) (Horne, 2013). Performance can also be measured by analyzing new prod- 
uct development, sales growth, customer satisfaction, and finally overall performance and customer satisfaction can be used as a measure of performance. The suitable measure of performance can be identified on the basis of strategic objectives of the enterprises. There are number of approaches in the enterprises to measure financial performance and the market effectiveness as well as the strategic objectives. Another important thing that should be kept in mind is that performance of MSEs especially in the developing countries like Pakistan cannot be measured on the basis of ROA or ROE because the owners of MSEs in such countries are mostly illiterate and do not keep accounting records, therefore, the performance has to be measured on the basis of perception of the owners regarding sales growth, customers' growth, assets growth, product growth, employment growth, and the enterprise reputation in the market (Asad, Sharif, \& Hafeez, 2016; Asad, Sharif, \& Alekam, 2016).

Many studies has been conducted and have compared the larger and the smaller enterprises and there are several significant differences. Several researchers and even few government departments consider MSEs as same, which is perhaps not the fact. MSE's are found similar in many matters and are different from the larger enterprises. But in certain situations micro enterprises have to face more difficulties as compared to small enterprises. Despite the fact there are insignificant differences but in few cases the differences become significant especially while considering risk taking. Therefore, the current study tried to analyze that either size moderates or not the relationship between entrepreneurial orientation and innovation and entrepreneurial orientation and performance.

On the basis of the above discussion the study is being conducted considering resource based view of the enterprise. According to resource based view the resources are vital for gaining competitive advantage. The study only differentiate innovation being independent to dependent on risk taking and pro-active behavior of the enterprises. Therefore, resource based theory is used to tell that how the enterprise should utilize its capabilities to gain competitive advantages. Considering the resource based view of the firm and the arguments raised in the study on the basis of literature review following framework has been developed which would be analyzed using structural equation modeling.

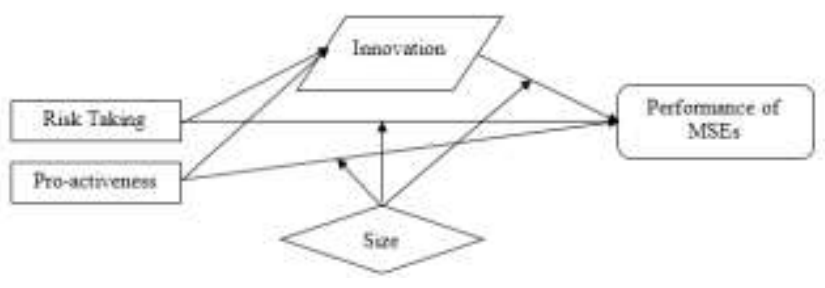

Figure 1:structure

\section{Research Method}

The study is exploratory in nature and is designed to test the resource-based view of the firm. The sample of 384 MSEs has been selected on simple random sampling basis from the entire province of Punjab. Punjab has been selected because more than $50 \%$ of the MSEs are operating in Punjab, Pakistan. All those MSEs that have less than 10 employees were termed as micro enterprises and all those that have employees between 10 and 20 are termed as small.

\subsection{Research Design}

Research design provides the guideline for conducting research. Research design in developed $\mathrm{n}$ the basis of research hypothesis and objectives of the study. The current research paper follows quantitative method. After ensuring normality of the data partial least square has been used for identifying the significance of direct relationships, mediating role and moderating effects (Hair, Ringle, $\&$ Sarstedt, 2013). For the purpose of collecting the data survey method has been adopted. The data has been collected from the owners of MSEs in Punjab Pakistan.

\subsubsection{Purpose of the study.}

The primary purpose of the study was to test the mediating role of innovation in the relationship between entrepreneurial orientation and performance of MSEs. Furthermore, this study tries to identify the effect of firm size over the relationship between entrepreneurial orientation and performance of MSEs and entrepreneurial orientation and innovation.

\subsubsection{Timeframe of the study.}

The study is cross sectional and will be conducted in three months' time period. The data collection will be done within the timeframe of three months.

\subsubsection{Research method.}

The study will follow survey research. Survey method was selected because survey method is most appropriate when the sample is to be collected from a large population and the results have to be generalized.

\subsubsection{Unit of analysis.}

Unit of analysis may be an individual or organization. In this study organizations are the unit of analysis. Therefore, in the current study MSEs are taken as unit of analysis. All the MSEs owners operating in Punjab can be the respondents of the study.

\subsection{Operationalization of Variables}

Four variables have been used in this study. Entrepreneurial orientation, innovation, firm size, and performance of MSEs. The variables have been operationalized as follows.

\subsubsection{Entrepreneurial orientation.}

Entrepreneurial orientation has been further divided into two dimensions. Risk taking and pro activeness. Another dimension is commonly used i.e. autonomy, but it is ignored because the study is to be conducted on MSEs so the role of autonomy is nullified as in MSEs there is one owner who takes the decisions and the concept of autonomy is out of question.

\subsubsection{Risk taking.}

Risk taking means the propensity of the MSE to take risk of investing in research and development innovation and to take risk of entering new markets (Asad, Sharif, \& ALekam, 2016).

\subsubsection{Pro-activeness.}

Pro-activeness means the propensity of the MSE to be pioneer in entering new market or developing new product of adopting a new method of production (Asad, Sharif, \& Hafeez, 2016).

\subsubsection{Innovation.}

Innovation means to innovate new products and services and to identify new ways of producing the products and services (Asad, Sharif, \& Alekam, 2016). The basic purpose is to enhance performance by using entrepreneurial orientation.

\subsubsection{Size.}

The size has been divided into two micro enterprises and small enterprises. The enterprises having less than 10 employees will be 
considered as micro enterprises and the enterprises having employees between 10 and 20 will be considered as small enterprises.

\subsubsection{Performance of MSEs.}

As the study is dealing with MSEs. The basic problem of these MSEs is informality. These MSEs especially in the developing countries like Pakistan do not keep formal accounting records therefore, the perception of the owners regarding sales growth, assets growth and product development have been taken as the measures of performance (Asad, Sharif, \& ALekam, 2016).

\subsection{Sampling and Population}

The entire province of Punjab, Pakistan was taken as population The list of MSEs operating in Punjab have been taken from SMEDA which from the sampling frame. On the basis of the formula a sample size of 384 was drawn (Zikmund, Babin, Carr, \& Griffin, 2012).

\subsection{Data Collection}

The self-administered questionnaire was sent to the potential respondents to along with a covering letter and self-addressed stamped envelope. This usually enhances the response rate. Furthermore follow-up calls were also made to the respondents who didn't responded with in the prescribed time of 15 days (Collis \& Hussey, 2009).

\subsection{Measurement of Variables}

The variables will be measured with the help of a structured questionnaire. The self-administrative seven point Likert scale questionnaire has been adopted to measure the variables. Seven point Likert scale is used because it is considered as more reliable in measuring the variable (Cooper \& Schindler, 2006).

\subsubsection{Reliability of the instrument.}

For ensuring the reliability of the research instrument, Cronbach's alpha has been calculated. If the calculated value of Cronbach's alpha is more than 0.7 then the scale is considered as reliable (Creswell, 2013). All the variables have a Cronbach's alpha value of above 0.7. The values are shown below in Table 3.1.

Table 3.1

\begin{tabular}{|ll|}
\hline \multicolumn{2}{|c|}{ Reliability analysis } \\
\hline Variable & Cronbach's alpha \\
\hline Risk taking & 0.813 \\
\hline Pro-activeness & 0.827 \\
\hline \multicolumn{2}{|c|}{ Innovation 0.759} \\
\hline Size $\quad 0.712$ \\
\hline Performance of MSEs 0.913 \\
\hline
\end{tabular}

\section{Data Analysis}

For analyzing the data, initially the data was entered in SPSS 22 The initial tests of normality were conducted on SPSS 22. The descriptive and the normality of the variables used in the study have been mentioned below in Table 4.1.

Table 4.1

\begin{tabular}{|llllll|}
\hline \multicolumn{2}{l}{ Descriptive and normality } & & & & \\
\hline $\begin{array}{l}\text { Variables Mean } \\
\text { sis }\end{array}$ & Std. Deviation & Variance & Skewness Kurto- & \\
\hline Risk taking & 4.1205 & 0.76781 & 0.5895 & -1.058 & -0.383 \\
\hline Pro-activeness & 4.2597 & 0.95093 & 0.9043 & -1.128 & -0.401 \\
\hline Innovation 3.8947 & 0.89563 & 0.8022 & -1.012 & 0.296 & \\
\hline Size 3.5590 & 0.63989 & 0.4095 & 1.249 & 0.587 & \\
\hline
\end{tabular}

$\begin{array}{llllll}\text { MSE Performance } & 4.1327 & 0.71519 & 0.5115 & -0.965 & -1.050\end{array}$

After ensuring that the data is good for analysis PLS3 was used for testing direct relationship, mediation, and moderation.

\subsection{Direct Relationships}

Initially, the direct relationships have been found to find the direct effects of risk taking on innovation, pro-activeness on innovation, innovation on performance of MSEs, risk taking on performance of MSEs, and pro-activeness on performance of MSEs. The results of the analysis are as follows in table 4.2:

Table 4.2

\begin{tabular}{|lllll|}
\hline Direct relationships & \multicolumn{5}{l|}{} \\
\hline Paths Path coefficients & \multicolumn{1}{l}{ T statistics P values } & & \\
\hline Risk taking->Innovation & 0.31 & 4.11 & 0.00 & \\
\hline Pro-activeness->Innovation & 0.10 & 2.03 & 0.02 & \\
\hline Innovation->Performance of MSEs & 0.12 & 1.97 & 0.03 \\
\hline Risk taking->Performance of MSEs & 0.20 & 2.46 & 0.01 \\
\hline Pro-activeness->Performance of MSEs & 0.38 & 4.60 & 0.00 \\
\hline
\end{tabular}

\subsection{Mediation Testing}

After ensuring that the direct relationship exists between the independent variables and the mediator and dependent variable and mediator and the dependent variables, mediation tests have been conducted:

Table 4.3

\begin{tabular}{|lll|}
\hline \multicolumn{2}{|l|}{ Mediation testing } & \\
\hline Paths Path coefficients T statistics P values & & \\
\hline $\begin{array}{l}\text { Risk taking->Innovation->Performance of MSEs } \\
0.04\end{array}$ & 0.03 & 1.97 \\
\hline $\begin{array}{l}\text { Pro-activeness->Innovation->Performance of MSEs } \\
0.01\end{array}$ & 0.05 & 2.19 \\
\hline
\end{tabular}

The significance of mediating variable is calculated by dividing the product of the two significant paths with the standard error of the two significant paths to get the $t$ values which shows that mediation is significant or not, in this analysis innovation mediates both the relationships between risk taking and performance and pro-activeness and performance.

\subsection{Moderation Tests}

After ensuring that the mediation is significant the next step is to identify the effect of enterprise size over the relationship among risk taking, pro-activeness, and innovation, and relationship among risk taking, pro-activeness, and performance of MSEs.

Table 4.4

\begin{tabular}{|lrrr|}
\hline \multicolumn{4}{|l|}{ Moderation testing } \\
\hline Paths Path coefficients T statistics P values & & \\
\hline Risk taking*Size->Performance of MSEs & 0.26 & 1.98 & 0.030 \\
\hline Pro-activeness*Size->Performance of MSEs 0.27 & 2.01 & 0.008 \\
\hline Innovation*Size->Performance of MSEs & 0.32 & 2.21 & 0.001 \\
\hline
\end{tabular}

The path coefficients are significant. This shows that size of the enterprises moderates the relationship between risk taking and performance, pro-activeness and performance and innovation and performance.

\section{Conclusions}

The current era is very competitive, all enterprises take the challenge of innovation to survive in the competitive environment. Innovation is also important for the enhancement of profits in the local markets. MSEs are now moving towards new markets by 
innovation. According to the new markets for earning more profits. Enterprises try to make them different by making different criteria through the development of new policies. These new policies are adopted to look different. Enterprises try to make enhancement for performing better in the market. This study was being conducted to investigate the factor that may directly or indirectly influence performance. Through this research it has been identified that entrepreneurial orientation and innovation are very important for improvement in performance of MSEs. Innovation plays a significant mediating role to enhance performance. The degree of entrepreneurial orientation and the level of innovation is higher in small enterprises as compared to micro enterprises.

\subsection{Suggestions for Future Research}

As discussed earlier, much of the studies were conducted on the large enterprises or relatively medium sized enterprises. Previous studies have mainly compared the large enterprises with small enterprises. Hardly any study was found that was conducted on the comparison between MSEs, despite the fact that MSEs constitute a major portion in the economy of Pakistan. Further research is needed in the area to investigate the similarities of the different sizes of the enterprises in the different context especially it has been observed that entrepreneurial networking has a major role for enhancing the performance of MSEs. Addition of entrepreneurial networking and other factors that are considered important only for large or medium enterprises may also provide fruitful results for enhancing the performance of MSEs.

\section{References}

[1] Abe, M., Troilo, M., Juneja, J., \& Narain, S. (2012). Policy Guidebook for SME Development in Asia and the Pacific. Bangkok: United Nations Economic and Social Commission for Asia and the Pacific

[2] Aftab, M., \& Naveed, T. A. (2013). Role of microfinance institutions in entrepreneurship development in district Gujrat, Pakistan. Journal of Global and Scientific Issues, 1(1), 53-69.

[3] Ahlin, B., Drnovšek, M., \& Hisrich, R. D. (2013). Entrepreneurs' creativity and firm innovation: The moderating role of entrepreneurial self-efficacy. Small Business Economics, 43(1), 101-117. doi:10.1007/s11187-013-9531-7

[4] Ali, S. (2013). The small and medium enterprises and poverty in Pakistan: An empirical analysis. European Journal of Business and Economics, 8(2), 25-30.

[5] Aloulou, W., \& Fayolle, A. (2005). A conceptual approach of entrepreneurial orientation within small business context. Journal of Entreprising Culture, 3(1), 21-45.

[6] Andersona, B. S., \& Eshima, Y. (2013). The influence of firm age and intangible resources on the relationship between entrepreneurial orientation and firm growth among Japanese SMEs. Journal of $\begin{array}{lll}\text { Business Venturing, } & \text { 28(3), }\end{array}$ doi:10.1016/j.jbusvent.2011.10.001

[7] Andersson, M., \& Lööf, H. (2012). Small business innovation: Firm level evidence from Sweden. The Journal of Technology Transfer, 37(5), 732-754. doi:10.1007/s10961-011-9216-9

[8] Aribaba, F. O., Asaolu, T. O., \& Olaopa, O. (2011). An evaluation of the impact of technological innovative entrepreneurial development programmes on the performance of small scale business in Nigeria. Global Journal of Business,Management And Accounting, 1(1), 001-009.

[9] Asad, M., Sharif, M. N., \& Alekam, J. M. (2016). Moderating role of entrepreneurial networking on the relationship between access to finance and performance of MSEs in Punjab Pakistan. Paradigms A Research Journal of Commerce, Economics, and Social Sciences, 10(1), 1-13.

[10] Asad, M., Sharif, M. N., \& ALekam, J. M. (2016). Moderating role of entrepreneurial networking on the relationship netween entrepreneurial orientation and performance of MSEs in Punjab Pakistan. Science International, 28(2), 1551-1556.

[11] Asad, M., Sharif, M. N., \& Hafeez, M. (2016). Moderating effect of network ties on the relationship between entrepreneurial orientation, market orientation, and performance of MSEs. Paradigms A Research Journal of Commerce, Economics, and Social Sciences, $10(2), 74-81$
[12] Vu Van TUAN Communicative Competence of the Fourth Year College Students: Basis for proposed English Language Program, Astra Salvensis, Supplement No. 2, 2017, p. 45

[13] [1] Irina MALGANOVA, Andrey ERMAKOV, Development of heating Devices from Polypropylene, Astra Salvensis, Supplement No. 2, 2017, p. 93

[14] Jana Arturovna KLAAS, Thomas Arturovich KLAAS Econometric Model of Early Diagnosis of a Credit Institution Bankruptcy Risk, Astra Salvensis, Supplement No. 2/2017, p. 107.

[15] Gulnaz Mavletzyanovna GALEEVA, Olga Aleksandrovna AKTASHEVA Forecasting the Dynamics of Foreign Direct Investment in the Russian Economy, Astra Salvensis, Supplement No. 2/2017, p. 137

[16] Kamil Maratovich ARSLANOV, Artur Ilfarovich KHABIROV About the Weak Party of the Loan Contract, Astra Salvensis, Supplement No. 2/2017, p. 323

[17] Cooper, D. R., \& Schindler, P. S. (2006). Business Research Methods. Chicago: McGraw-Hill Irwin.

[18] Covin, J. G., \& Lumpkin, G. (2011). Entrepreneurial orientation theory and research: Reflections on a needed construct. Entrepreneurship Theory and Practice, 35(5), 855-872. doi:10.1111/j.15406520.2011.00482.x

[19] Shatilova L.M., Borisova V.V., Kasatkina O.A. (2018). Representation of the linguistic and cultural concept "lie" in the French and Russian language picture of the world, 34(85), Pp. 194-212.

[20] 2 Bakhyt S., Kalimbetov B., Khabibullayev Z. (2018). Possibilities of Mathematical Problems in Logical Thinking, Development of Secondary Education Pupils, 34(85), P.p. 321-338.

[21] Hafeez, M. H., Shariff, M. N., \& Lazim, H. B. (2012). Relationship between entrepreneurial orientation, firm resources, SME branding and firm's performance: Is innovation the missing link. American Journal of Industrial and Business Management, 2, 153-159.

[22] Hair, J. F., Ringle, C. M., \& Sarstedt, M. (2013). Editorial-partial least squares structural equation modeling: Rigorous applications, better results and higher acceptance. Long Range Planning, 46(1), $1-12$.

[23] Horne, J. C. (2013). Fundamentals of Financial Management . London: McGraw Hill.

[24] Inmyxai, S., \& Takahashi, Y. (2010). The effect of firm resources on business performance of male-and female-headed firms in the case of Lao micro-, small-, and medium-sized enterprises (MSMEs) International Journal of Business, 5(1), 63-90.

[25] Kovaleva, S., \& Vries, N. d. (2016). Competitive strategies, perceived competition and firm performance of micro firms: The case of Trento. Contemporary Entrepreneurship, 75-93. doi:10.1007/978-3-319-28134-6 5

[26] Kreiser, P. M., Marino, L. D., Kuratko, D. F., \& Weaver, K. M. (2013). Disaggregating entrepreneurial orientation: The non-linear impact of innovativeness, proactiveness and risk-taking on SME performance. Small Business Economics, 40(2), 273-291. doi:10.1007/s11187-012-9460-x

[27] Lechner, C., \& Gudmundsson, S. V. (2012). Entrepreneurial orientation, firm strategy and small firm performance. International Small Business Journal, 32(1), 36-60. doi:10.1177/0266242612455034

[28] Lee, S. Y., Florida, R., \& Acs, Z. (2004). Creativity and entrepreneurship: A regional analysis of new firm formation. Regional Studies, 38(8), 879-891. doi:10.1080/0034340042000280910

[29] Madsen, E. L. (2007). The significance of sustained entrepreneurial orientation on performance of firms - A longitudinal analysis. Entrepreneurship \& Regional Development: An International Journal, 19(2), 185-204. doi:10.1080/08985620601136812

[30] McMullen, J. S., \& Shepherd, D. A. (2006). Entrepreneurial action and the role of uncertainty in the Theory of the Entrepreneur. Academy of Management Review, 31(1), 132-152. doi:10.5465/AMR.2006.19379628

[31] O'Regan, N., \& Ghobadian, A. (2004). Testing the homogeneity of SMEs: The impact of size on managerial and organisational processes. European Business Review, 16(1), 64 - 77. doi:org/10.1108/09555340410512411

[32] Rauch, A., Wiklund, J., Lumpkin, G., \& Frese, M. (2009). Entrepreneurial orientation and business performance: An assessment of past research and suggestions for the future. Entrepreneurship Theory and Practice, 33(3), 761-787. doi:10.1111/j.15406520.2009.00308.x

[33] Rosenbusch, N., Brinckmann, J., \& Bausch, A. (2011). Is innovation always beneficial? A meta-analysis of the relationship between 
innovation and performance in SMEs. Journal of Business Venturing, 26(4), 441-457. doi:10.1016/j.jbusvent.2009.12.002

[34] Rubera, G., \& Kirca, A. H. (2012). Firm innovativeness and its performance outcomes: A meta-analytic review and theoretical integration. Journal of Marketing, 76(3), 130-147. doi:http://dx.doi.org/10.1509/jm.10.0494

[35] Runyan, R., Droge, C., \& Swinney, J. (2008). Entrepreneurial Orientation versus small business orientation: What are their relationships to firm performance? Journal of Small Business Management, 46(4), 567-588. doi:10.1111/j.1540-627X.2008.00257.x

[36] Sahut, J.-M., \& Peris-Ortiz, M. (2013). Small business, innovation, and entrepreneurship. Small Business Economics, 42(4), 663-668. doi:10.1007/s11187-013-9521-9

[37] Shabbir, M. S., Mohd Shariff, M. N., Kiran, R., Faisal, M., \& Shahzad, A. (2016). Cyber entrepreneurship: A note on indigenous perspective from a developing country. Social Sciences (Pakistan). http://doi.org/10.3923/sscience.2016.704.709

[38] Shabbir, M. S., Shariff, M. N. M., Salman, R., \& Shabbir, M. F. (2017). Exploring the link between entrepreneurial skills and entrepreneurial intentions: Proposing a hypothesized model for future research. Paradigms: A Research Journal of Commerce, Economics, and Social Sciences, 11(1), 72-77.

[39] Shabbir, M. S., Shariff, M. N. M., \& Shahzad, A. (2016a). A Conceptual Development of Entrepreneurial Skills and Entrepreneurial Intentions: A Case of IT employees in Pakistan. International Journal of Academic Research in Business and Social Sciences, 6(3). http://doi.org/10.6007/IJARBSS/v6-i3/2040

[40] Shabbir, M. S., Shariff, M. N. M., \& Shahzad, A. (2016b). A Conceptual Development of Entrepreneurial Skills and Entrepreneurial Intentions A Case of IT employees in Pakistan A Conceptual Development of Entrepreneurial Skills and Entrepreneurial Intentions : A Case of IT employees in Pakistan. International Journal of Academic Research in Business and Social Sciences, 6(3), 65-78. http://doi.org/10.6007/IJARBSS/v6-i3/2040

[41] Shabbir, M. S., Shariff, M. N. M., \& Shahzad, A. (2016c). Mediating role of perceived behavioral control and stakeholders' support system on the relationship between entrepreneurial personal skills and entrepreneurial intentions of it employees in Pakistan. International Business Management. http://doi.org/10.3923/ibm.2016.1745.1755

[42] Shabbir, M. S., Shariff, M. N. M., Yusof, M. S. Bin, Salman, R., \& Hafeez, S. (2018). Corporate Social Responsibility and Customer loyalty in Islamic Banks of Pakistan: A Mediating Role of Brand Image. Academy of Accounting and Financial Studies Journal, 22(Special Issue), 1-6.

[43] Simon, M., Stachel, C., \& Covin, J. G. (2011). The effects of entrepreneurial orientation and commitment to objectives on performance. New England Journal of Entrepreneurship, 14(2), 1-9.

[44] Zikmund, W., Babin, B., Carr, J., \& Griffin, M. (2012). Business Research Methods. Masson: Cengage Learning. 